\title{
MicroRNA-19b Associates with Ago2 in the Amygdala Following Chronic Stress and Regulates the Adrenergic Receptor Beta 1
}

\author{
Naama Volk, ${ }^{1,2}$ Evan D. Paul, ${ }^{2,3}$ Sharon Haramati, ${ }^{1}$ Chen Eitan, ${ }^{1}$ Brandon K.K. Fields, ${ }^{3}$ Raaya Zwang, ${ }^{1}$ Shosh Gil, ${ }^{1}$ \\ Christopher A. Lowry, ${ }^{3}$ and Alon Chen ${ }^{1,2}$ \\ ${ }^{1}$ Department of Neurobiology, Weizmann Institute of Science, Rehovot 76100, Israel, ${ }^{2}$ Department of Stress Neurobiology and Neurogenetics, Max Planck \\ Institute of Psychiatry, Munich 80804, Germany, and ${ }^{3}$ Department of Integrative Physiology, University of Colorado Boulder, Boulder, 80309 Colorado
}

Activation of the stress response in the presence of diverse challenges requires numerous adaptive molecular and cellular changes. To identify specific microRNA molecules that are altered following chronic stress, mice were subjected to the chronic social defeat procedure. The amygdala from these mice was collected and a screen for microRNAs that were recruited to the RNA-induced silencing complex and differentially expressed between the stressed and unstressed mice was conducted. One of the microRNAs that were significantly altered was microRNA-19b (miR-19b). Bioinformatics analysis revealed the adrenergic receptor $\beta-1$ (Adrb1) as a potential target for this microRNA with multiple conserved seed sites. Consistent with its putative regulation by miR-19b, Adrb1 levels were reduced in the basolateral amygdala (BLA) following chronic stress. In vitro studies using luciferase assays showed a direct effect of miR-19b on Adrb1 levels, which were not evident when miR-19b seed sequences at the Adrb1 transcript were mutated. To assess the role of miR-19b in memory stabilization, previously attributed to BLA-Adrb1, we constructed lentiviruses designed to overexpress or knockdown miR-19b. Interestingly, adult mice injected bilaterally with miR-19b into the BLA showed lower freezing time relative to control in the cue fear conditioning test, and deregulation of noradrenergic circuits, consistent with downregulation of Adrb1 levels. Knockdown of endogenous BLA-miR-19b levels resulted in opposite behavioral and noradrenergic profile with higher freezing time and increase 3-methoxy4-hydroxyphenylglycol/noradrenaline ratio. These findings suggest a key role for miR-19b in modulating behavioral responses to chronic stress and Adrb1 as an important target of miR-19b in stress-linked brain regions.

Key words: adrenergic receptor beta 1; Ago2; amygdala; microRNA; stress

\section{Introduction}

The amygdala has a central role in regulating the behavioral stress response following stressful and emotional stimulation (Galvez et al., 1996). Amygdalar adrenergic receptor $\beta 1$ (Adrb1) was previously shown to affect anxiety-like behavior (Rudoy and Van Bockstaele, 2007; Fu et al., 2008) and fear memory (Roozendaal et al., 2004, 2006a). The Adrb1 is expressed in various stress-related

\footnotetext{
Received March 3, 2014; revised Sept. 8, 2014; accepted Sept. 13, 2014.

Author contributions: N.V., S.H., C.A.L., and A.C. designed research; N.V., E.D.P., S.H., C.E., B.K.-K.F., R.Z., and S.G. performed research; N.V., E.D.P., and A.C. analyzed data; N.V., C.A.L., and A.C. wrote the paper.

This work is supported by an FP7 Grant from the European Research Council (260463), a Research Grant from the Israel Science Foundation (803/11), a Research Grant from the Israel Multidisciplinary Center for Mass Trauma Research (I-CORE), a Research support from Roberto and Renata Ruhman, Nella and Leon Benoziyo Center for Neurological Diseases, the Henry Chanoch Krenter Institute for Biomedical Imaging and Genomics, the Perlman Family Foundation, Founded by Louis L. and Anita M. Perlman, the Adelis Foundation, the Marc Besen and the Pratt Foundation, and the Irving I. Moskowitz Foundation. A.C. is the head of the Max Planck Society-Weizmann Institute of Science Laboratory for Experimental Neuropsychiatry and Behavioral Neurogenetics. We thank Sharon Ovadia for his devoted assistance with animal care, and Stefan Engelhardt, Director Institute of Pharmacology and Toxicology, Technische Universitaet Muenchen (TUM), Munich, Germany for providing the adrenergic receptor beta 1 knock-out mice.

The authors declare no competing financial interests.

Correspondence should be addressed to Dr Alon Chen, Department of Neurobiology, Weizmann Institute of Science, Rehovot, 76100, Israel. E-mail: alon.chen@weizmann.ac.il.

DOI:10.1523/JNEUROSCI.0855-14.2014

Copyright $\odot 2014$ the authors $\quad 0270-6474 / 14 / 3415070-13 \$ 15.00 / 0$
}

brain nuclei including the amygdala, hippocampus, and paraventricular nucleus of the hypothalamus (PVN). Infusion of $\beta$-adrenergic receptor antagonists into the amygdala blocks the modulation of memory storage by the stress-related hormones epinephrine and glucocorticoids (McGaugh et al., 1996), whereas drugs that enhance memory increase levels of noradrenaline in the amygdala (Hatfield and McGaugh, 1999). Interestingly, studies have convincingly demonstrated that the consolidation of aversive memories is facilitated by crosstalk between glucocorticoids, noradrenergic, and cannabinoid signaling in the basolateral nucleus of the amygdala (BLA; Roozendaal et al., 2006b). The regulation of the adrenergic receptor protein levels in the BLA is important for consolidation of emotionally aversive memories and coping with stressful challenges (Hill and McEwen, 2009). However, data regarding stress-dependent mechanisms mediating the protein levels of adrenergic receptors in the BLA is limited. Regulation at the transcript level of these receptors might enable a fast response during changing conditions and may be mediated by specific microRNA (miRNA) molecules.

miRNAs are short $(\sim 22$ nucleotide), endogenous, singlestranded RNA molecules that regulate gene expression by promoting RNA transcript degradation or translation inhibition of target mRNAs. Several studies have reported that a range of be- 
havioral and pharmacological manipulations alters miRNA levels in adult mouse or rat brain structures (Uchida et al., 2008; Meerson et al., 2010; Lin et al., 2011; Issler et al., 2014). We previously reported an increase in several miRNAs including miR-34c in the amygdala $90 \mathrm{~min}$ following acute restraint stress (Haramati et al., 2011). miR-34c was found to regulate the stressrelated corticotropin-releasing factor receptor type 1 , and had a protective effect against stress-induced anxiety when lentivirally overexpressed in the mouse central amygdala. In addition, the brain enriched miRNA, miR-128b, was found to be upregulated following fear-extinction (Lin et al., 2011). Notably, changes in miRNA levels are not necessarily indicative for their immediate activity; it is only when a specific miRNA has matured, and has been incorporated into the RNA-induced silencing complex (RISC) in the presence of argonaute RISC catalytic component 2 (Ago2), where it associates with its target mRNA, that it is truly active (Meister et al., 2004).

To identify specific miRNAs that are activated (recruited to the RISC complex) following chronic stress, we have isolated and analyzed the Ago2-associated miRNAs in the amygdala of mice subjected to a social defeat protocol. One such prominent miRNA is miR-19b, which we further demonstrated both in vitro and in vivo to be a major regulator of Adrb1 levels and related behavioral functions.

\section{Materials and Methods}

Animals

Male C57BL/6J and ICR (outbred mice strain, also known as CD1) mice (Harlan) were maintained in a pathogen-free temperature-controlled $\left(22 \pm 1^{\circ} \mathrm{C}\right)$ mouse facility on a reverse $12 \mathrm{~h}$ light/dark cycle at the Weizmann Institute of Science, according to institutional guidelines. Food (Harlan) and water were given ad libitum. The total number of animals used for the Ago2 IP was 30 (18 social defeat and 12 control). The total number of animal used for the lentiviruses injected mice was 40 in total (10/group).

\section{Chronic social defeat}

Ten-week-old C57BL/6J mice were subjected to a social defeat protocol as previously described (Krishnan et al., 2007). Briefly, the mice were placed in a homecage of an aggressive ICR mouse and allowed to physically interact for $5 \mathrm{~min}$. During this time, the ICR mouse attacked the intruder mouse and the intruder displayed subordinate posturing. A perforated clear Plexiglas divider was then placed between the animals and the mice remained in the same cage for $24 \mathrm{~h}$ to allow sensory contact. The procedure was then repeated with an unfamiliar ICR mouse for each of the 10 consecutive days. Control mice were housed in the same room as the social defeat mice but were escorted out of the room during the 5 min interaction with the ICR. Control mice were handled daily and housed two in a cage with a perforated clear Plexiglas divider placed between the two mice.

\section{Microdissection of brain sites for Ago2 IP}

Amygdala samples were collected from social defeat and control mice $8 \mathrm{~d}$ after the end of the social defeat protocol. Tissue collection and processing was as previously described (Sztainberg et al., 2010; Lebow et al., 2012). Briefly, after removing the brain and placing it on an acryl $1 \mathrm{~mm}$ brain matrix (Stoelting, Catalog \#51380), slices of $2 \mathrm{~mm}$ were taken using standard razor blades (GEM, 62-0165) based on designated anatomical markers. Blunted syringes at different diameters were used to extract the amygdala from slices removed from the matrix.

\section{Immunoprecipitation of Ago2 protein}

Pools of three amygdala from three mice from the same treatment group (either social defeat $n=18$ or control $n=12$ ) were homogenized in NP40 buffer, which was supplemented with RNase inhibitor, protease inhibitor and phosphatase inhibitor (Roche). The samples were constantly agitated for $2 \mathrm{~h}$ at $4^{\circ} \mathrm{C}$. Samples were then centrifuged for $20 \mathrm{~min}$ at $12,000 \mathrm{rpm}$ at $4^{\circ} \mathrm{C}$ in a microcentrifuge; the supernatant was placed in a fresh tube kept on ice and the pellet was discarded. Magnetic protein $G$ beads (Dynabeads, Invitrogen) were incubated with the Ago2 monoclonal antibody (WAKO) with rotation at room temperature for $10 \mathrm{~min}$. After several washes, the samples were added to the Ago2-coated protein $\mathrm{G}$ beads and incubated overnight at $4^{\circ} \mathrm{C}$ under agitation. The following day the beads were washed three times with PBS. For RNA purification, the beads were homogenized in RLT buffer (RNeasy kit, miRNA supplementary protocol). For Western blot analysis, the beads were boiled in sample buffer to release the protein from the beads.

\section{RNA purification and microarray}

RNA from the Ago2 immunoprecipitation samples was isolated using the RNeasy plus kit (Qiagen) following Qiagen supplementary Protocol 1: purification of total RNA containing miRNA. RNA for all other purposes was isolated from frozen brain punches using miRNeasy mini kit (Qiagen) according to the manufacturer recommendation. RNA derived from tissues of stressed mice following Ago 2 immunoprecipitation was further analyzed on Affymetrix miRNA 2.0 array (enriched RNA protocol).

\section{Bioinformatic analysis of microRNA microarray results}

miRNAs and genes were tested in 3 different web based programs in search for a seed match between a miRNA and a 3' UTR: Target Scan (http://www.targetscan.org), Miranda (http://www.microrna.org; Betel et al., 2008), and Pictar (http://pictar.mdc-berlin.de).

Cloning of 3' UTRs into Psicheck2 luciferase expression plasmid 3' UTR sequence of Adrb1 was PCR amplified from mouse genomic DNA using a forward primer with an NdeI site: CATATGGCTTCTC CTCGGAGTCCA, and a reverse primer: CCATCAACTCAATAACATA ATAGACAA. The DNA sequence for the mutated form of Adrb1 (lacking all 4 seed sites of miR-19b) was purchased from Epoch Life Science. 3' UTR fragments were then ligated into pGem-T easy vector (Promega) according to the manufacturer's guidelines, and further subcloned into a single NotI site at the $3^{\prime}$ end of luciferase in the Psicheck2 reporter plasmid (Promega). Cloning orientation was verified by diagnostic cuts and sequencing.

\section{Transfections and luciferase assay}

HEK293T and HT-22 cells were grown on poly-L-lysine-coated 48-well plates to a $70-85 \%$ confluence and transfected using polyethylenimine with the following plasmids: 5 ng of Psicheck2-3' UTR plasmid and 215 ng of EGFP overexpressing vector for either a specific miRNA, or an empty EGFP plasmid. Twenty-four hours following transfection, cells were lysed and luciferase reporter activity was assayed as previously described (Chen et al., 2005). Renilla luciferase values were normalized by control luciferase levels (transcribed from the same vector but not affected by the 3' UTR tested) and averaged across eight well repetitions per condition.

\section{miRNA RT-qPCR expression analysis}

Quantitative miRNA expression was acquired and analyzed using a step one thermocycler (Applied Biosystems), using primers that were designed for specific miRNA. RNA samples were assessed using miScript Reverse transcription kit and SYBRGreen PCR kit (Qiagen) according to the manufacturer's guidelines. U6 snRNA was used as internal control. Gene expression was obtained using the High Capacity kit and cybr green PCR master mix (Applied Biosystems). The real time PCR primers for Adrbl were as follows: forward: TCATGGCCTTCGTGTACCTG; and reverse: TTACCTGTTTTTGGGCCTCG.

\section{Western blot analysis}

Frozen brain samples were homogenized in RIPA buffer supplemented with proteinase inhibitors (Sigma-Aldrich) and were incubated on ice for $10 \mathrm{~min}$. After $10 \mathrm{~min}$ centrifugation, the supernatant was transferred to a new tube and sample buffer was added to the sample, which was then boiled for $5 \mathrm{~min}$ and placed on ice. The samples were separated in a $10 \%$ PAGE. Transfer was performed using an assembly of nitrocellulose membrane and Whatman paper. The transfer was performed at $100 \mathrm{~V}$, $350 \mathrm{mAmp}$ for $1 \mathrm{~h}$. After washes with PBST (PBS $+20 \%$ Tween 20) 
membrane was blocked with $10 \%$ milk. The first antibody was added (rabbit anti-Adrb1, Santa Cruz Biotechnology, sc-568; mouse antiGAPDH, Abcam, ab8245) to PBST and placed on constant shaking at $4^{\circ} \mathrm{C}$ overnight. The second antibody (anti-rabbit HRP, anti-mouse HRP) was added in $10 \%$ milk for $1 \mathrm{~h}$. Each step was separated by additional washes with PBST. Finally, ECL was added to the membrane, which was then exposed to film.

Design, construction, and validation of miR-19 lentiviruses miR-19b overexpression vector was cloned as follows: the enhanced form of human synapsin I promoter (Hioki et al., 2007) was PCR amplified (forward primer: ttttttatcgatctcgagtagttattaatagtaatc; reverse primer: ttttttaccggtggcgcgccegccgcagcgcagatggt) from pENTR1A-E/SYN-GFPWRPE1 (kindly provided by Dr Takeshi Kaneko, Department of Morphological Brain Science, Graduate School of Medicine, Kyoto University, Kyoto, Japan) and inserted between ClaI and AgeI restriction sites to replace the CMV promoter in pCSC-SP-PW-GFP (kindly provided by Dr Inder Verma, The Salk Institute for Biological Studies, La Jolla, CA). Following the Synapsin promoter the precursor for miR-19b was inserted as follows: GTCCTGTTATTGAGCACTGGTCTATGGTT AGTTTTGCAGGTTTGCATCCAGCTGTATAATATTCTGCTGTGCA AATCCATGCAAAACTGACTGTG. The H1-miR-19b KD and its control scramble sequence were obtained from GeneCopoeia and subcloned into the NheI site of the p156RRL-CMV-GFP viral plasmid. High titer lentiviruses were produced as described previously (Tiscornia et al., 2006). Briefly, recombinant lentiviruses were produced by transient transfection in HEK293T cells. Infectious particles were harvested at 48 and $72 \mathrm{~h}$ post-transfection, filtered through $0.45-\mu \mathrm{m}$-pore cellulose acetate filters, concentrated by ultracentrifugation, redissolved in sterile HBSS, aliquot, and stored at $-80^{\circ} \mathrm{C}$.

\section{Stereotactic intracranial injections}

A computer-guided stereotaxic instrument and a motorized nanoinjector (Angle Two Stereotaxic Instrument, myNeurolab) were used as previously described (Elliott et al., 2010; Kuperman et al., 2010; Regev et al., 2012). Mice were anesthetized using $1.5 \%$ isoflurane and $1 \mu \mathrm{l}$ of the lentiviral preparation was delivered to each basolateral amygdala using a Hamilton syringe connected to a motorized nanoinjector system at a rate of $0.2 \mu \mathrm{l}$ per $\min$ (coordinates relative to bregma: $\mathrm{AP}=-1.58 \mathrm{~mm}, \mathrm{~L}=$ $\pm 3.3 \mathrm{~mm}, \mathrm{H}=-4.6 \mathrm{~mm}$ ). Mice were subjected to behavioral studies following a 2 week recovery period.

\section{Behavioral assessments}

All behavioral assessments were performed during the dark active phase of the mice following habituation to the test room for $2 \mathrm{~h}$ before each test. Behavioral tests were conducted as previously described (Haramati et al., 2011; Lebow et al., 2012) in the following order, from the least stressful procedure to the most and ending with homecage locomotor testing: Open-field, dark/light transfer test, elevated plus maze, fear conditioning, and homecage locomotion.

Open-field test. The open-field test was performed in a $50 \times 50 \times 22$ $\mathrm{cm}$ white box, lit to 120 lux. The mice were placed in the box for $10 \mathrm{~min}$. Locomotion in the box was quantified using a video tracking system (VideoMot2; TSE Systems).

Dark/light transfer test. The dark/light transfer test apparatus consists of a polyvinyl chloride box divided into a black dark compartment $(14 \times$ $27 \times 26 \mathrm{~cm})$ and a connected white 1200 lux illuminated light compartment $(30 \times 27 \times 26 \mathrm{~cm})$. During the $5 \mathrm{~min}$ test, time spent in the light compartment, distance traveled in light, and number of light/dark transitions were quantified with a video tracking system (VideoMot2; TSE Systems).

Elevated plus-maze. This apparatus in this test is designed as a plus sign and contains two barrier walls and two open arms. During the 5 min test, which is performed in relative darkness (6 lux), number of entries, distance traveled and the time spent in the open arms is automatically scored using a video tracking system (VideoMot2, TSE Systems).

Fear conditioning. A computer-controlled fear-conditioning system (TSE Systems) monitored the procedure while measuring freezing behavior (defined as lack of movement except for respiration). On the first day, mice were habituated for $5 \mathrm{~min}$ to the fear conditioning chamber, a clear Plexiglas cage $(21 \mathrm{~cm} \times 20 \mathrm{~cm} \times 36 \mathrm{~cm})$ with a stainless steel floor grid within a constantly illuminated (250 lux) fear conditioning housing. Conditioning took place on day 2 in one 5 min training session. Mice initially explored the context for $2 \mathrm{~min}$. Thereafter, two pairings of a coterminating tone [conditioned stimulus (CS): $30 \mathrm{~s}, 3000 \mathrm{~Hz}$, pulsed 10 $\mathrm{HZ}, 80 \mathrm{~dB}(\mathrm{~A})$ ] and shock [unconditioned stimulus (US): $0.7 \mathrm{~mA}, 2 \mathrm{~s}$, constant current] with a fixed intertrial interval (ITI) of $60 \mathrm{~s}$. The US was delivered through the metal grid floor. Mice were removed from this chamber $1 \mathrm{~min}$ after the last CS-US pairing. The chamber was cleaned thoroughly with $10 \%$ ethanol before each session. The ventilating fan of the conditioning box housing provided a constant auditory background noise [white noise, $62 \mathrm{~dB}(\mathrm{~A})$ ]. Context-dependent memory was tested $24 \mathrm{~h}$ after the conditioning by re-exposure to the conditioning box for 5 min without any stimuli. The tone-dependent cued-memory test was performed $1 \mathrm{~d}$ after the contextual memory test in a novel context: the walls and floor of the box were opaque black Plexiglas (dimensions were similar to the conditioning box), and the apparatus house lights and ventilating fan were turned off. Behavior was monitored for $2 \mathrm{~min}$ without any stimulus before the CS (tone) presentations; thereafter two CSs were presented, separated by a fixed $1 \mathrm{~min}$ ITI. Mice were removed from this box 1 min after the last CS.

Homecage locomotion. Homecage locomotion was assessed using the InfraMot system (TSE Systems). Mice were housed individually for $72 \mathrm{~h}$, in which the first $24 \mathrm{~h}$ were considered habituation to the individual housing conditions. Measurements of general locomotion consisted of two light and two dark cycles in the last $48 \mathrm{~h}$ collected at $10 \mathrm{~min}$ intervals.

\section{Microdissections, sample preparation, and HPLC-ED analysis of NE and MHPG concentrations}

Microdissections were performed as previously described (Palkovits and Brownstein, 1988; Evans et al., 2008; Neufeld-Cohen et al., 2010). Briefly, coronal brain sections $(300 \mu \mathrm{m})$ were taken using a Leica CM1950 cryostat (North Central Instruments), mounted onto glass slides, and microdissected on a cold plate at $-10^{\circ} \mathrm{C}$ under a stereomicroscope using microdissection needles with varying inner diameters. Each microdissected brain structure for each subject was put into separate individual tubes each containing $100 \mu \mathrm{l}$ of acetate buffer $(3.0 \mathrm{~g} / \mathrm{L}$ sodium acetate, 4.3 $\mathrm{ml} / \mathrm{L}$ glacial acetic acid, $\mathrm{pH}$ adjusted to 5.0 ), which were rapidly frozen on dry ice and stored at $-80^{\circ} \mathrm{C}$. Next, samples were thawed and then centrifuged at $4^{\circ} \mathrm{C}$ and 13,000 rpm for $3 \mathrm{~min}$. The supernatant was aspirated and $50 \mu \mathrm{l}$ of the supernatant was used for detection of noradrenaline (NE) and 3-methoxy-4-hydroxyphenylglycol (MHPG) using high performance liquid chromatography with electrochemical detection (HPLC-ED), which has been previously described (Heal et al., 1989; Evans et al., 2008), but with slight modifications. The pellet was reconstituted with $175 \mu \mathrm{l}$ of $0.2 \mathrm{M} \mathrm{NaOH}$ for later assay of protein content. Samples were placed in an ESA model 542 autosampler to automatically inject the samples into the HPLC system. The HPLC system also consisted of an ESA Model 582 Solvent Delivery Module to pump the mobile phase $(0.1 \mathrm{M}$ sodium acetate/citric acid buffer dissolved in HPLC grade $\mathrm{H}_{2} \mathrm{O}, \mathrm{pH} 4.40$, adjusted with semiconductor grade $\mathrm{NaOH}$, containing $8 \%$ HPLC grade methanol (v/v), and $4.6 \mathrm{~mm}$ octanesulphonic acid) through the chromatographic system. The stationary phase, where chromatographic separation occurred, consisted of an integrated precolumn/ column system [Ultrasphere 5 ODS $(\mathrm{C} 18)$ precolumn $(45 \times 4.6 \mathrm{~mm}) /$ Ultrasphere 5 ODS $(\mathrm{C} 18)$ column $(250 \times 4.6 \mathrm{~mm})$; MAC-MOD Analytical] maintained at RT. Electrochemical detection was accomplished using an ESA Model 5200A Coulochem II detector with dual potentiostats connected to an ESA 5021 Conditioning Cell with the electrode potential set at $0 \mathrm{mV}$ and an ESA 5014B Microdialysis Cell with the channel 1 and channel 2 electrode potentials set at -200 and $400 \mathrm{mV}$, respectively. For each run, the average peak heights of known concentrations of NE and MHPG were determined manually using chromatography analysis software (EZChrom Elite for Windows, v2.8, Agilent Technologies) and used to calculate the concentration of the unknown samples. Tissue concentrations of NE and MHPG were standardized to the amount of protein in each microdissected structure. 
A

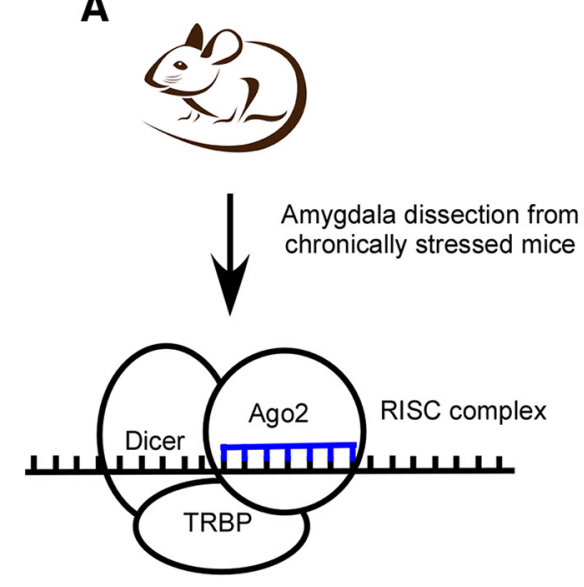

B

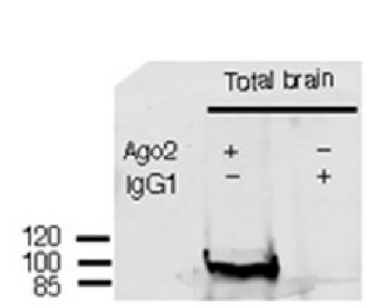

C

Ago2 IP / IGg1 IP
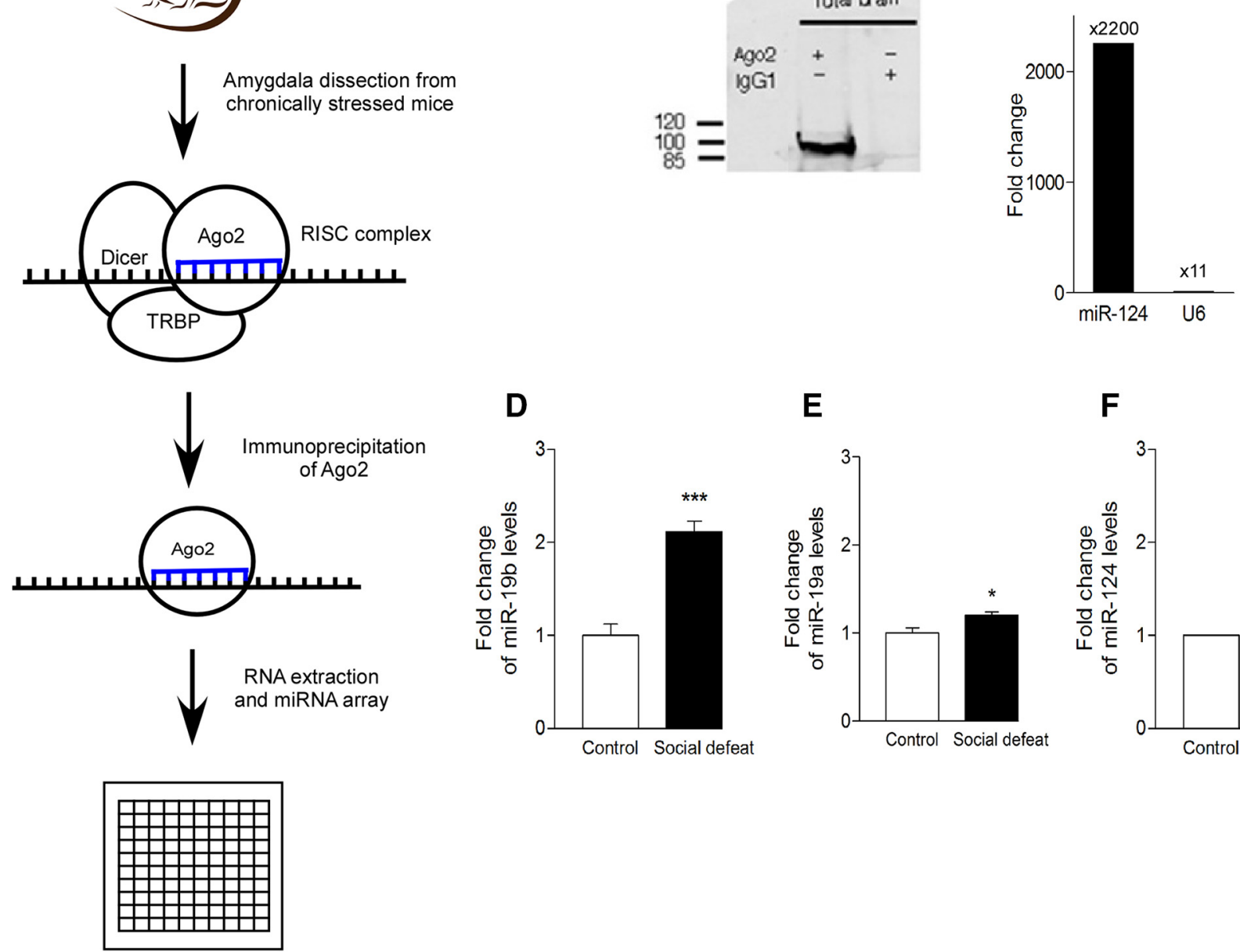

Figure 1. miR-19b is upregulated in amygdala-Ago2 extract following chronic stress. A, Ago2-RNA IP was performed and RNA extracted from the Ago2 complex was analyzed on an Affymetrix array. $\boldsymbol{B}, \boldsymbol{C}$, The validity of the Ago2-RNA IP was confirmed using Western blot (B) and RT-PCR (C). D-F, The Ago2 IP revealed a robust elevation of miR-19b (D) a slight elevation of miR-19a (E) and no change in miR-124 levels $(\boldsymbol{F})$.

\section{Statistics}

The Student's $t$ test was used to assess significance. For behavioral results of lentiviral-injected mice, Student's $t$ test was used between control and miR-19b overexpression (OE) or knockdown (KD)-injected mice. Factor analysis was performed using SPSS software to determine which scores should be given to which tests. For the miRNA array results a $q$ value correction was performed.

\section{Results}

MiR-19b associates with Ago2 in the amygdala following chronic stress

To identify miRs recruited to the RISC complex specifically during chronic stress we immunoprecipitated (Rodriguez-Gonzalez et al., 2008) Ago2 and its associated RNAs from the amygdala of chronically stressed mice (Fig. $1 A$ ). To validate that the immunoprecipitation indeed resulted in RNA bound to Ago2, the protein soluble fraction from total brain tissue was extracted, and the Ago2 protein-RNA complex was precipitated using anti-Ago2coated beads. As a control we used nonspecific IgG1-coated beads (Fig. $1 B$ ). The RNA fraction was extracted from the Ago 2 immunoprecipitated material by conventional methods. To verify that miRNAs were indeed precipitated with Ago2, we performed real time PCR with primers specific to miR-124 or U6. MiR-124 is highly abundant in the brain and indeed its levels were found to be 2200-fold enriched in the Ago2 IP fraction relative to the control (Fig. 1C). The levels of U6, which is not expected to be associated with Ago2 in the RISC complex were only elevated 11-fold in the Ago2 IP (Fig. 1C) demonstrating the specificity of the Ago2 IP. To identify the entire repertoire of miRs associated with the RISC complex we performed a miRNA microarray (Exiqon) with the RNA fraction extracted from the amygdala Ago2 IP of the chronically stressed or control mice.

Analysis of the miRs that were specifically associated with Ago 2 in the brains of chronically stressed mice relative to the control group identified miR-19b as the miR that showed a maximal elevation $\left(\sim 2\right.$-fold, $F_{(1,9)}=41.14, p<0.001$; Fig. $\left.1 D\right)$. This increase was specific to miR-19b, as the levels of miR-19a were only slightly elevated $\left(\sim 1.2\right.$-fold, $F_{(1,9)}=9.043, p<0.05$; Fig. $\left.1 E\right)$ and miR-124 was not significantly increased following a similar treatment (Fig. $1 F$ ). An additional group of miRs that were elevated 1.5 -fold included $\sim 30$ miRs of 757 in total (data not shown).

\section{miR-19b regulates Adrb1 levels}

Bioinformatic analysis revealed Adrb1 as a possible mRNA target of miR-19b. This receptor has four seed matches for miR-19b, 


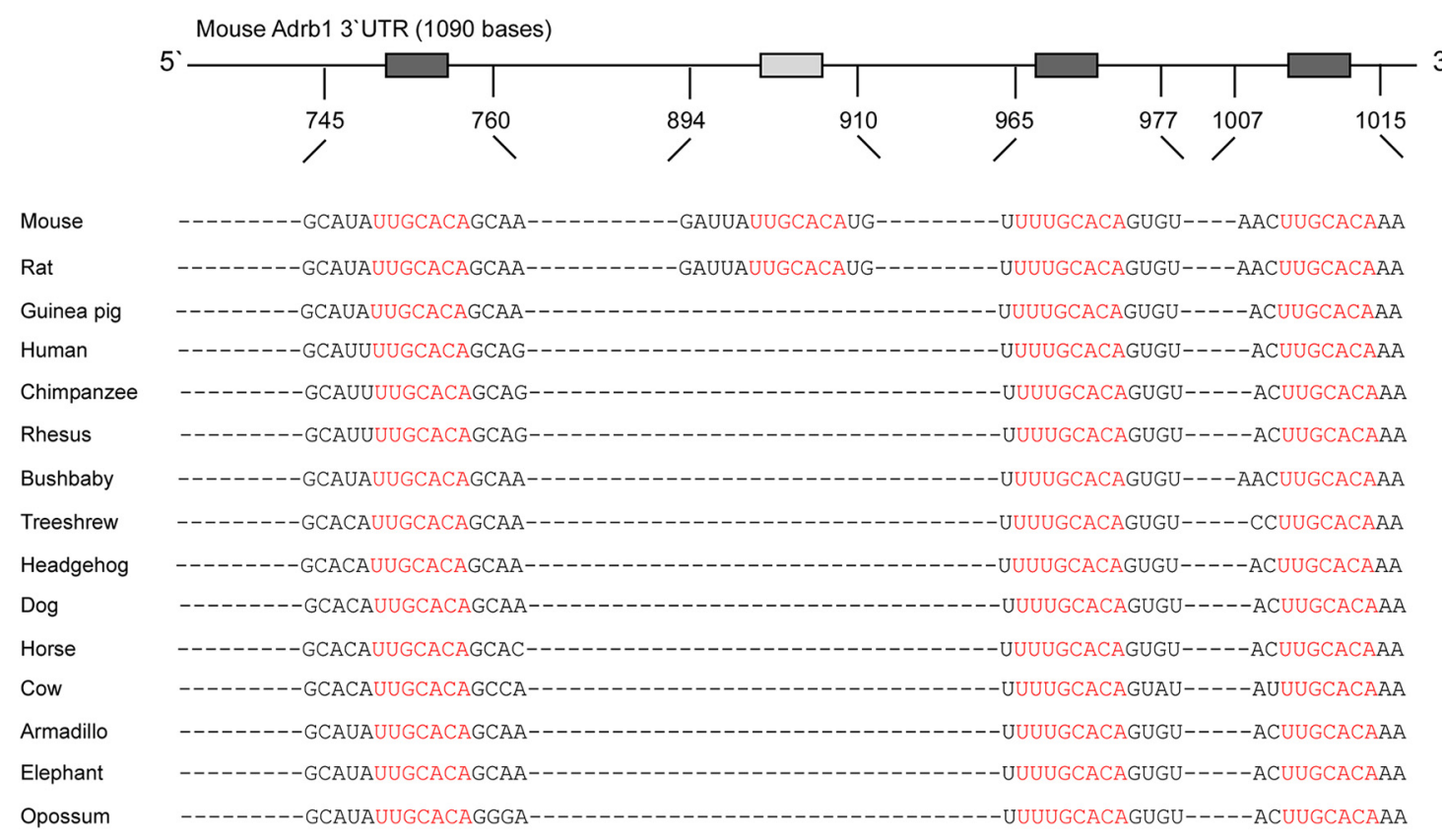

Figure 2. Schematic illustration of the 3' UTR of Adrb1 transcripts showing four putative seed matches for miR-19b and seed conservation in multiple organisms.

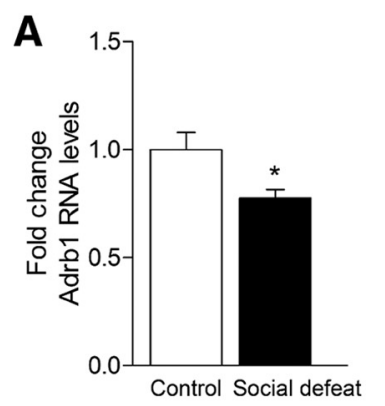

B

Adrb1

GAPDH

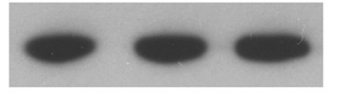

C

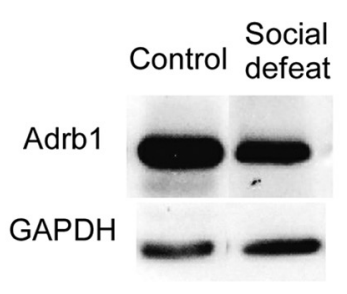

D

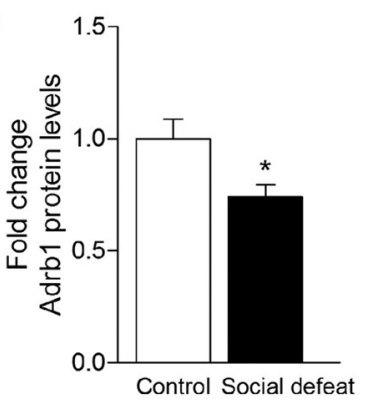

Figure 3. Amygdala Adrb1 protein levels are reduced in mice subjected to chronic social defeat paradigm. $A$, Real-time PCR analysis of Adrb1 RNA levels in the BLA of mice subjected to chronic social defeat. $\boldsymbol{B}$, WB analysis of Adrb1 levels in WT, Adrb1 ${ }^{ \pm}$and Adrb1 ${ }^{-1-}$ mice. $C, D$, WB analysis of Adrb1 protein in the BLA of mice subjected to chronic social defeat paradigm. Representative blot $(\boldsymbol{C})$ and quantification of four repetitions $(\boldsymbol{D})$ are presented.

three of these are conserved and one is present only in mouse and rat (Fig. 2).

Adrenergic receptors in the BLA have been reported to play a role in memory consolidation. Enhanced noradrenaline release in the BLA promotes memory consolidation. To examine whether the levels of Adrb1 are altered during social defeat in the BLA, brain tissue punches from the BLA were collected from chronically stressed and control mice and the mRNA and protein levels of Adrb1 were analyzed using real time PCR and Western blot analysis, respectively (Fig. 3). Real-time PCR analysis showed a decrease of $\sim 25 \%$ (Fig. $3 A$ ) in the Adrb1 transcript levels of the stressed mice $\left(n=5, F_{(1,9)}=6.393, p<0.05\right)$. To confirm the observed changes of Adrb1 transcript levels in the protein levels, we first validated the specificity of the anti-Adrb1 antibody. Isolated BLA tissue obtained from WT, Adrb ${ }^{ \pm}$and Adrb $1^{-1-}$ mice was analyzed using Western blot. Figure $3 B$ clearly shows that Adrb1 is not detected in the Adrb1-deficient mice, supporting the specificity of the anti-Adrb1 antibody used. Western blot analysis showed that the levels of Adrb1 were de- creased by $\sim 30 \%$ (Fig. 3C,D) in the BLA of chronically stressed mice relative to control $\left(n=4, F_{(1,9)}=6.394, p<0.05\right)$.

To address a functional link between miR-19b and Adrb1, we expressed the luciferase gene fused to wild-type Adrb1 3' UTR or mutated Adrb1 3' UTR lacking all four seed sites (Fig. 4A) in neuronal hippocampal cell line (HT-22) and compared the luciferase activity produced by the two constructs. The HT-22 neuronal cells express very low endogenous levels of miR-19, and consequently no difference was detected between the two constructs carrying wild-type or mutated luciferase-Adrb1 3' UTR sequence (Fig. 4B). However, cotransfection of the HT-22 with miR-19b expression construct, led to reduction of $\sim 50 \%(n=8$, $\left.F_{(1,15)}=69.19, p<0.001\right)$ in the luciferase activity of the luciferase-Adrb1 3' UTR relative to the control (Fig. 4C). The two luciferase-Adrb1 3' UTRs were also transfected into HEK293T cells, which express endogenously high levels of miR-19b. This resulted in a relative reduction of $50 \%\left(n=8, F_{(1,15)}=121.348\right.$, $p<0.001)$ in the luciferase activity in an Adrb1 3' UTRdependent manner (Fig. 4D). Together, these experiments dem- 


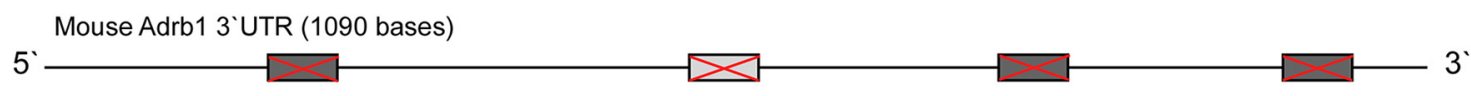

B

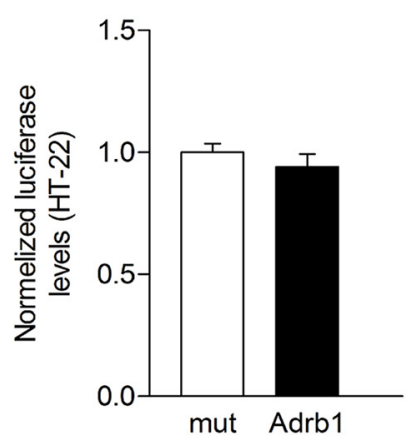

C

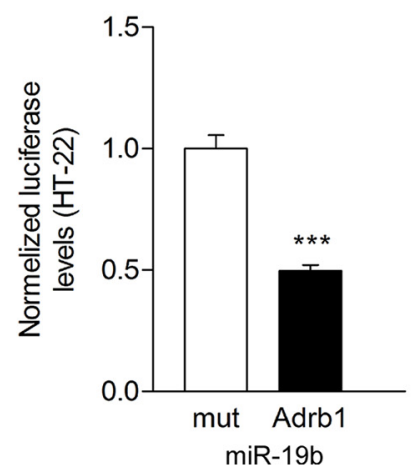

D

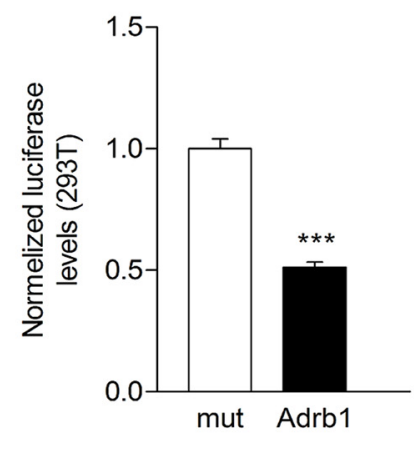

Figure 4. miR-19b regulates Adrb1 levels in vitro by binding to its $3^{\prime}$ UTR. $A$, Schematic illustration of the mutated form of the Adrb1 $3^{\prime}$ UTR, lacking the four seed matches for miR-19b. B-D, In vitro luciferase assay assessing the effect of miR-19b on the $3^{\prime}$ UTR of Adrb1 transcript. Luciferase assay in HT-22 cells that express low endogenous levels of miR-19b, without the presence of miR-19b (B) or in the presence of exogenous miR-19b (C). Luciferase assay in HEK293T cells that express high endogenous levels of miR-19b (D).

onstrate that miR-19b in culture conditions is capable of efficiently regulating Adrb1 through its 3' UTR.

\section{BLA-specific miR-19b overexpression or knockdown affects auditory fear memory but not anxiety-like behavior}

To examine the behavioral effects of miR-19b overexpression in the BLA of adult mice, a lentiviral vector expressing miR-19b under the neural-specific promoter synapsin was designed, constructed and produced (Fig. 5A). The precursor of miR-19b was cloned into a lentiviral construct and GFP sequences were fused at the $3^{\prime}$-end of the miR. A similar vector lacking the miR-19b sequences was used as a control (Fig. 5A). Viral infection of the two constructs into the hypothalamic mouse cell line N42 followed by real time PCR analysis indicated that the RNA levels of miR-19b were elevated $\sim 6$-fold $\left(n=3, F_{(1,5)}=148.909, p<\right.$ 0.001 ) in the infected cells (Fig. $5 B$ ), indicating an efficient production of the miR by the viral vector. A lentiviral vector expressing miR-19b knockdown or scramble sequences under the $\mathrm{H} 1$ promoter was designed, constructed, and produced (Fig. 5C). Infection of HEK293T cells with the knockdown viruses resulted in $\sim 2$-fold decrease in endogenous miR-19b levels relative to scrambled control $\left(n=3, F_{(1,5)}=13.435, p<\right.$ 0.05; Fig. $5 D$ ), indicating an efficient inhibition of the miR by the viral infection.

To analyze the behavioral effect of BLA-miR-19b overexpression or knockdown in adult mice, the viruses were injected bilaterally into the BLA of 10 -week old C57BL/6J mice ( $n=10$ in each group; Fig. $5 E-H$ ). Following 3 weeks of recovery, the mice were subjected to the fear-conditioning test, which assess learning and memory performance following an aversive stimulus. According to previous reports (Qu et al., 2008), decreased levels of Adrb1 are associated with reduce freezing time in the fear-conditioning procedure. Based on our analysis above it was predicted that overexpression or knockdown of miR-19b in the BLA would lead to a decrease or increase of Adrb1 levels, respectively. In the first day of the experiment (habituation) no differences were observed in the basal freezing levels between the different groups (Fig. $6 A, E$ ). Following a day of conditioning (Fig. $6 B, F$ ), in which the mice received two electrical shocks paired with a conditioned stimulus (tone), a "context test" (Fig. 6C, G) and a "cue test" (Fig. $6 D, H)$ were performed. Freezing behavior during the context test, which are primarily associated with the hippocampus (Kim and Fanselow, 1992), was not significantly different between the overexpressing or knockdown groups of mice and their respective controls (Fig. 6C,G). However, in the cue test, we found that mice overexpressing miR-19b froze $40 \%$ less $\left(n=10, F_{(1,19)}=\right.$ $6.234, p<0.05$ ) than the control group (Fig. 6D), suggesting a reduced memory consolidation. Intriguingly, mice injected with miR-19b knockdown viruses froze $60 \%$ more $\left(n=10, F_{(1,17)}=\right.$ 4.922, $p<0.05)$ than the control scrambled injected group (Fig. $6 H$ ).

The overexpressing and knockdown groups of mice and their respective controls were also subjected to anxiety-like behavior assessments, including the open-field, dark/light transfer and the elevated plus maze tests. In the open-field procedure no changes were observed in time the mice spent in the center of the arena (Fig. 7A,F). Similarly, in the dark/light transfer tests, no significant differences between the groups were detected in the time spent in the light compartment (Fig. $7 B, G$ ). In addition, no significant differences between the groups were observed in the time spent in the open arms of the elevated plus-maze test (Fig. 7C, $H$ ), although the miR-19b knockdown group showed a strong tendency $\left(n=10, F_{(1,19)}=4.243, p=0.054\right)$ for increased time in the open arms (Fig. $7 H$ ). No significant differences were observed in the homecage locomotor activity of the tested groups of mice (Fig. $7 D, E, I, J$ ). Together, the behavioral experiments support a specific role for miR-19b in regulating auditory fear memory, which is potentially mediated by the influence of miR-19b on Adrb1. 
A

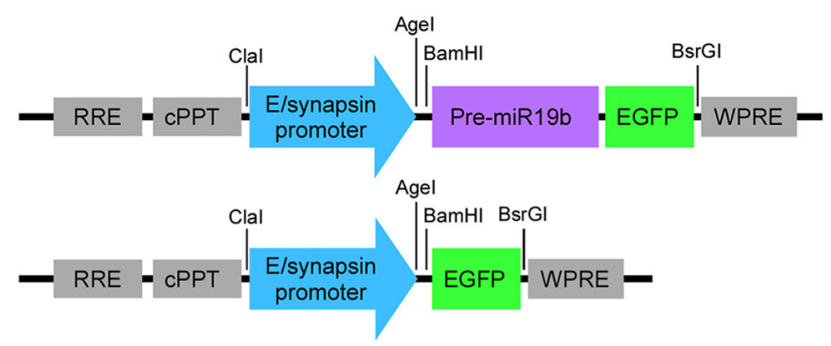

C

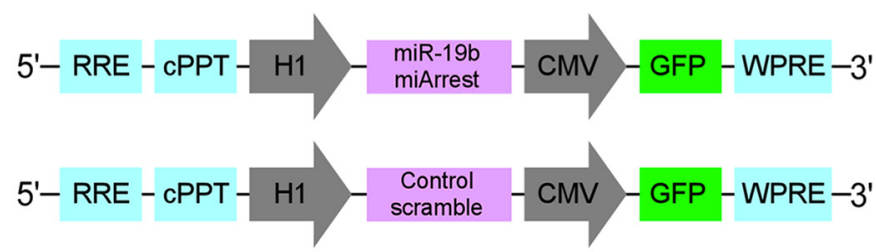

B

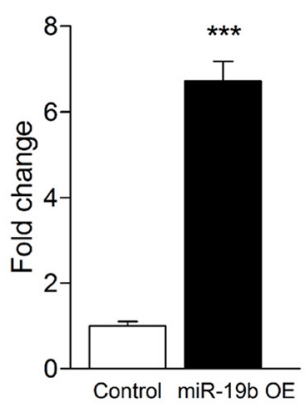

D

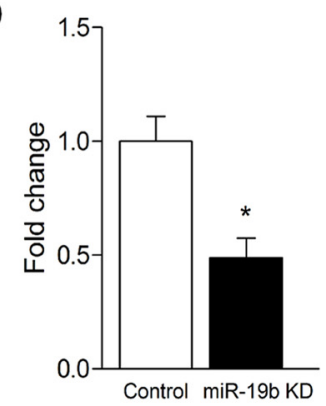

E

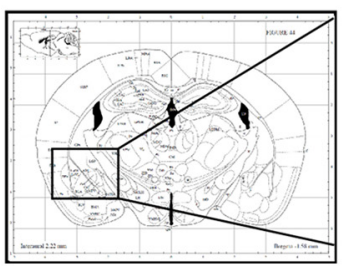

F

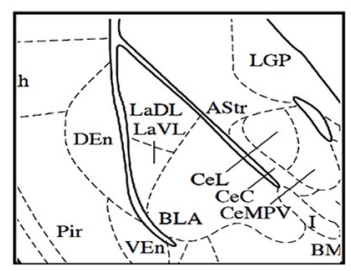

G

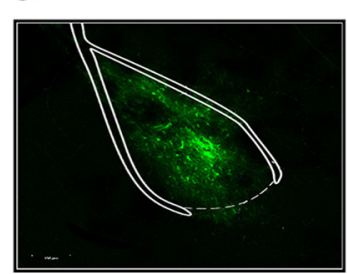

H

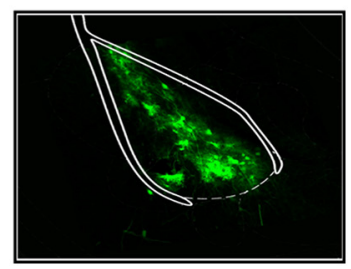

Figure 5. Establishment and validation of miR-19b overexpressing and knockdown lentiviruses. $\boldsymbol{A}$, Schematic illustration of the Syn-miR-19b OE and control lentiviral constructs. $\boldsymbol{B}$, Infection of N42 cells with the Syn-miR-19b OE virus showed an elevation of $\sim 6$-fold in miR-19b levels. C, Schematic illustration of the miR-19b knockdown (KD) and control lentiviral constructs. D, Infection of HEK293T cells with the miR-19b KD virus showed a decrease of $\sim 2$-fold in miR-19b levels. $E$, Schematic representation of site of delivery adopted from Paxinos and Franklin digital mouse brain atlas. $\boldsymbol{F}$, Enlargement of the basolateral amygdala region corresponding to the injection site. $\mathbf{G}, \boldsymbol{H}$, Representative microscope image of virally infected BLA at 10 weeks following miR-19b $0 \mathrm{E}$ (G) or miR-19b KD (H) virus injection.

\section{Downstream effects of BLA-specific miR-19b regulation on limbic circuits}

The effects of noradrenaline-induced BLA activation on memory consolidation are thought to be mediated by downstream signaling to limbic forebrain structures including the hippocampus and medial prefrontal cortex (Schwabe et al., 2012). Therefore, we predicted that BLA-specific modulation of miR-19b might alter signaling in downstream limbic structures. Noradrenaline acts via $\beta$ adrenergic receptors within the BLA to enhance excitatory neurotransmission both in vivo (Buffalari and Grace, 2007) and in vitro (Gean et al., 1992; Huang et al., 1996; Ferry et al., 1997). Because noradrenaline acts via $\beta$ adrenergic receptors within the BLA to activate glutamatergic projection neurons, and glutamate acts on presynaptic noradrenergic terminals to induce noradrenaline release in a number of limbic forebrain structures, including the prefrontal cortex (Russell and Wiggins, 2000) and hippocampus (Howells and Russell, 2008; Dazzi et al., 2011), we predicted that selective overexpression of miR-19b, by downregulating Adrb1 and noradrenalinemediated activation of glutamatergic projection neurons, would decrease noradrenergic signaling in specific downstream targets of the BLA. Complementarily, knockdown of miR-19b in the BLA may possibly result in an opposite affect by increasing Adrb1 levels.
Following the behavioral and locomotor activity tests, miR$19 \mathrm{~b}$ overexpressing or knockdown injected mice were sacrificed and noradrenaline and its degradation metabolite, MHPG, were measured in specific brain nuclei (Fig. $8 A-C$ ). A treatment $X$ region interaction for the MHPG:NE ratio $\left(F_{(4.56,82.0)}=3.38 ; p=\right.$ $0.01 ; \varepsilon=0.285)$ was observed. The BLA-specific miR-19b overexpression decreased the MHPG:NE ratio in the dorsal hippocampus (CA1d region) by $\sim 20 \%\left(F_{(1,17)}=5.213, p<0.05\right)$ as expected (Fig. $8 D$ ), suggesting that BLA-specific miR-19b overexpression not only influences noradrenergic signaling within the BLA, but also in a distributed system controlling memory consolidation (Roozendaal, 2000). Interestingly, the miR-19b knockdown group showed increase of $\sim 25 \%$ in the MHPG:NE ratio in the same brain region $\left(\mathrm{CA} 1 ; F_{(1,21)}=5.916, p<0.05\right.$; Fig. $8 G)$. The MHPG:NE ratios in the prelimbic (PrL) and infralimbic (IL) structures were unchanged (Fig. 8E,F,H,I). There was no treatment or treatment $\times$ region interactions for either the MHPG or NE concentrations alone.

\section{Discussion}

Adrb1 was previously demonstrated to play a pivotal role in regulating memory consolidation and stabilization (Roozendaal et al., 2004, 2006a) and anxiety-like behavior (Rudoy and Van Bockstaele, 2007; Fu et al., 2008). Therefore, modulating Adrb1 
A

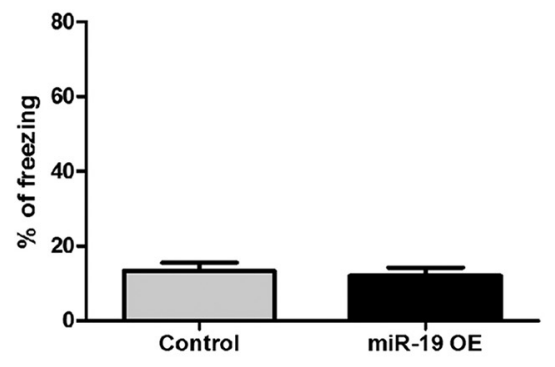

C

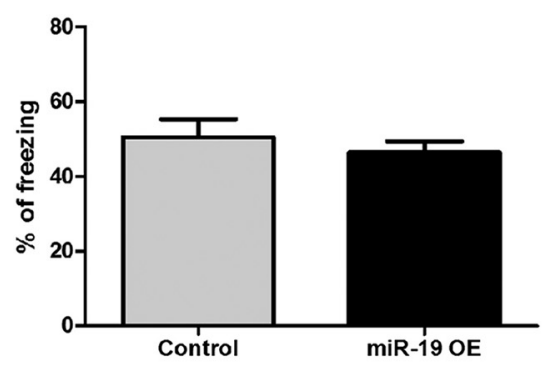

E

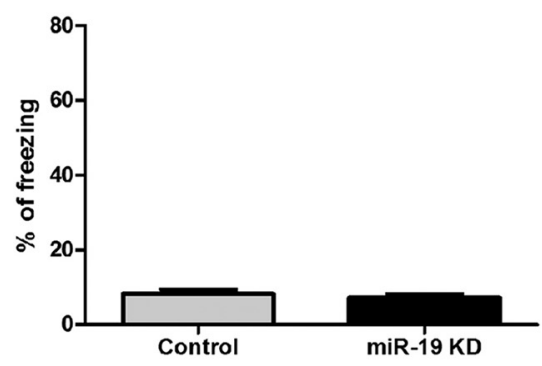

G

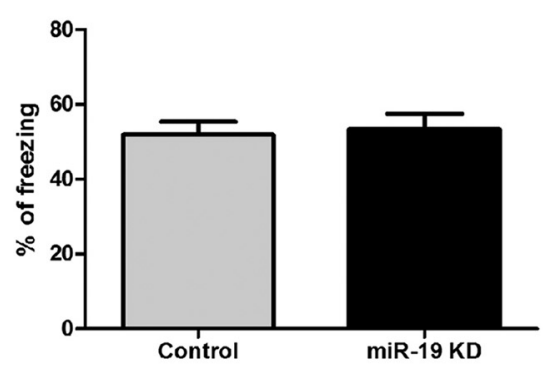

B

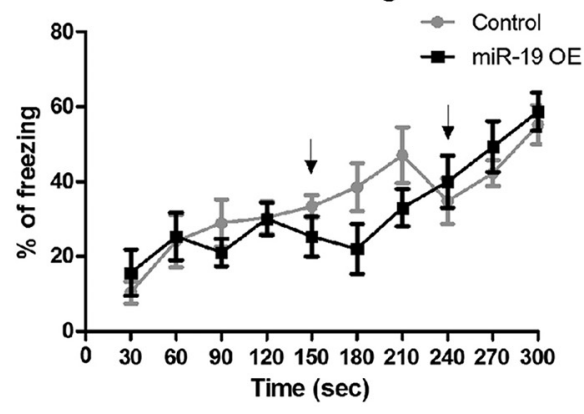

D

Cue test

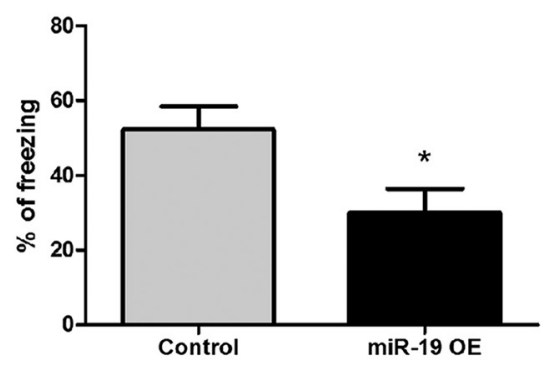

F

Fear training

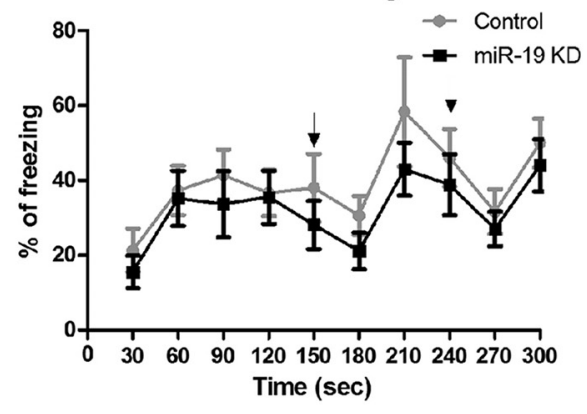

H Cue test

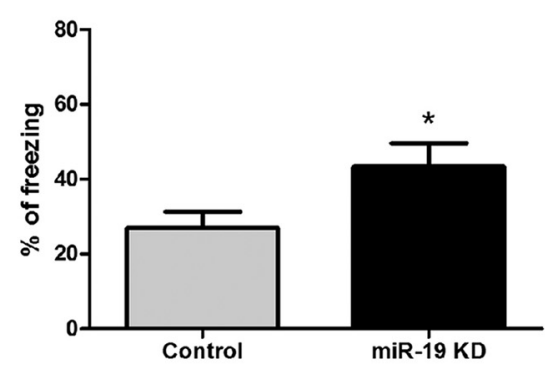

Figure 6. BLA-specific miR-19b overexpressing or knockdown mice showed changes in memory consolidation. $\boldsymbol{A}-\boldsymbol{H}$, Percentage of freezing in the fear conditioning paradigm $(n=10)$. Although no significant changes were observed in the percentage of freezing in the habituation $(\boldsymbol{A}, \boldsymbol{E})$, fear training $(\boldsymbol{B}, \boldsymbol{F})$, or context test $(\boldsymbol{C}, \boldsymbol{G})$, the BLA-specific miR-19b 0E mice showed significantly reduced percentage freezing in the Cue test $(\boldsymbol{D})$, whereas the BLA-specific miR-19b knockdown (KD) mice showed significantly elevated percentage freezing in the Cue test $(\boldsymbol{H})$.

levels and/or activity was proposed to be important for the regulation of stress-induced behavioral responses (Fortaleza et al., 2012). Here we identify miR-19b as an important novel modulator of Adrb1 in the BLA. MiR-19b levels were found to be significantly elevated in the RISC RNA-Ago2 complex in the amygdala region following the application of chronic social defeat (CSD) in mice, concomitant with a significant reduction in the transcript and protein levels of its putative target, Adrb1. These findings suggested a role for miR-19b in regulating amygdalar transcripts following chronic stress, and revealed Adrb1 as a key target and mediator of this process. Indeed our results demonstrate Adrb1 as a major target of miR-19b regulation. MiR-19b expression reduced the levels of a luciferase reporter fused to the $3^{\prime}$ UTR of Adrb1 in a manner that was dependent on the presence of four miR-19b seeds in its 3' UTR. Furthermore, changing the levels of BLA-miR-19b in adult mice using site-specific viral approach resulted in changes in freezing duration in the cue test of the fear-conditioning procedure. Whereas higher levels of miR-19b in the BLA resulted in reduced freezing in the cue test, lower levels of BLA-miR-19b caused an opposite effect, showing increased freezing behavior. These behavioral changes were also reflected in the opposed MHPG:NE ratio in the dorsal hippocampus suggest- 
A

Open field

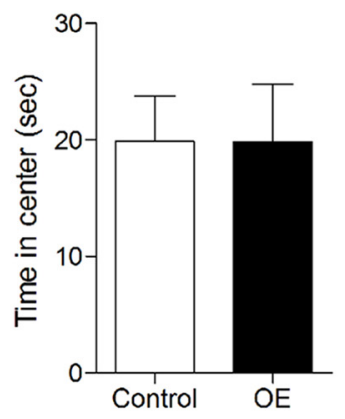

D

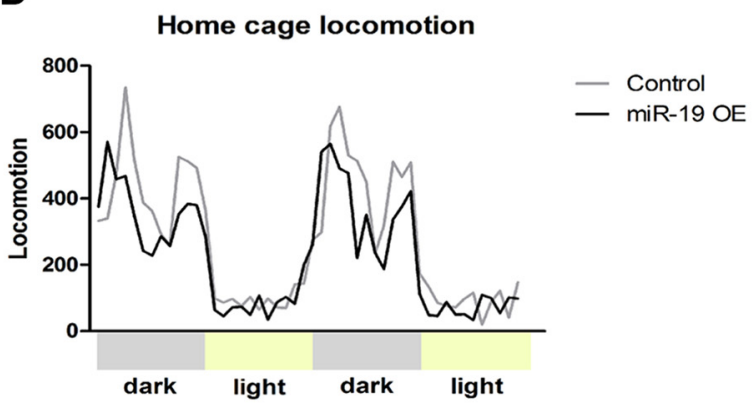

F

Open field

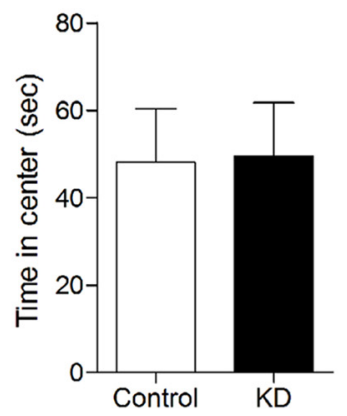

I

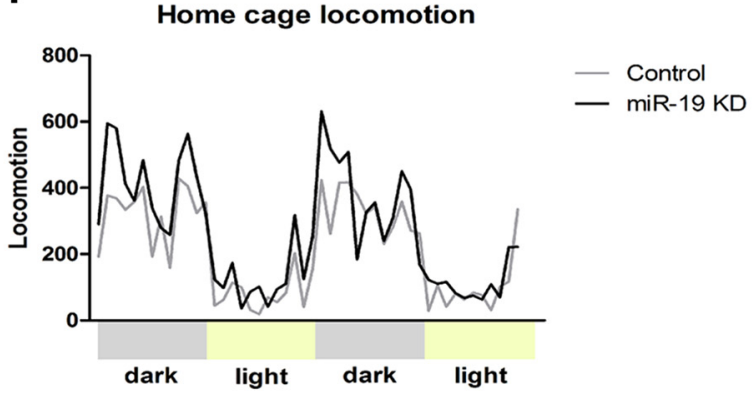

B

Dark light

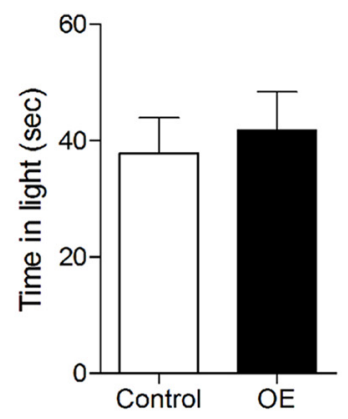

E

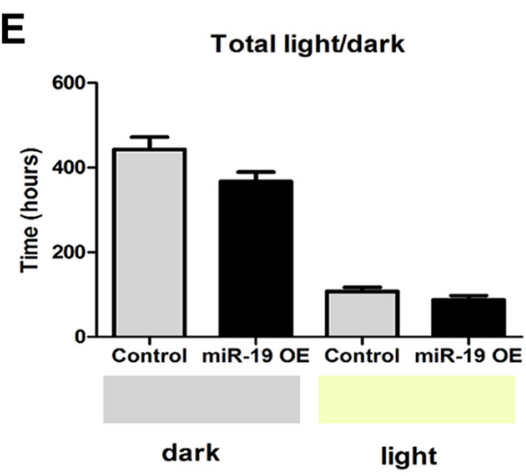

H

Elevated plus maze

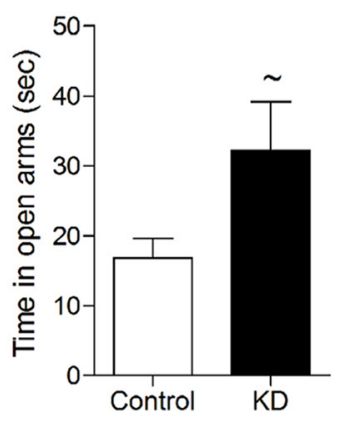

J

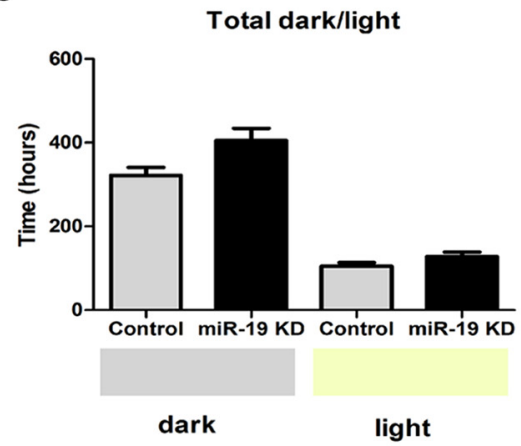

Figure 7. Intact anxiety-like behavior in mice expressing modified levels of miR-19 in the BLA. $\boldsymbol{A}-\boldsymbol{C}, \boldsymbol{F}-\boldsymbol{H}$, Anxiety-like behavior was assessed using the open-field $(\boldsymbol{A}, \boldsymbol{F})$, dark/light transfer ( $\boldsymbol{B}$, $\boldsymbol{G})$, and elevated plus maze $(\boldsymbol{C}, \boldsymbol{H})$ tests. The BLA-miR-19b OE or miR-19b KD groups of mice $(n=10)$ showed no significant differences in the anxiety parameters examined. $\boldsymbol{D}, \boldsymbol{E}, \boldsymbol{I}, \boldsymbol{J}$, No significant changes were observed in the homecage locomotor activity between the BLA-miR-19b OE mice and the control group $(\boldsymbol{D}, \boldsymbol{E})$ and the BLA-miR-19b KD mice and their respective control $(\boldsymbol{I}, J)$.

ing modified noradrenergic signaling in a distributed system controlling memory consolidation. These results suggest that BLA-miR-19b levels are important for the regulation of memory stabilization in response to stressful challenge, which is mediated primarily via modulating Adrb1 levels. The high BLA-miR-19b levels in the Ago 2 complex of chronically stressed mice reported in this study may be directly linked to the long-term regulation of the central stress response and related copying mechanisms. The 
A

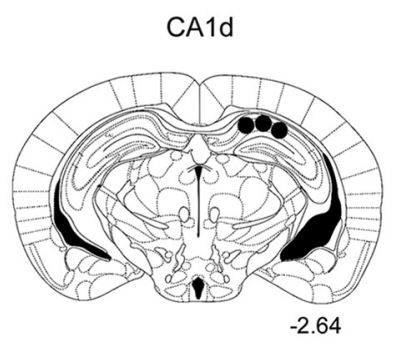

D

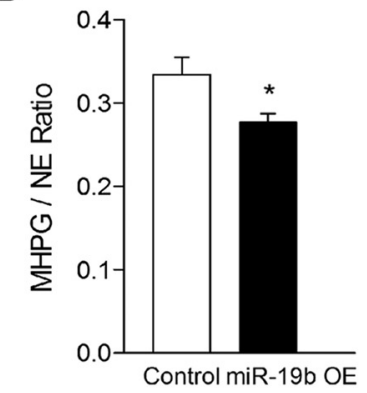

G

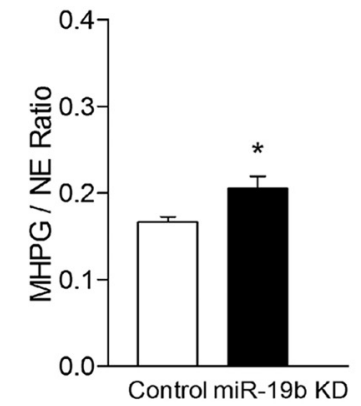

B

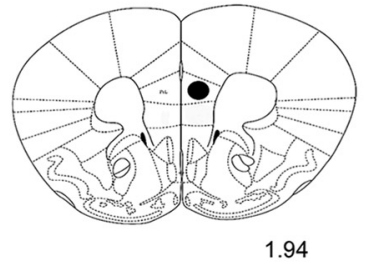

E

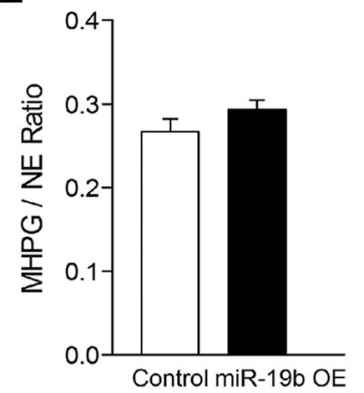

H

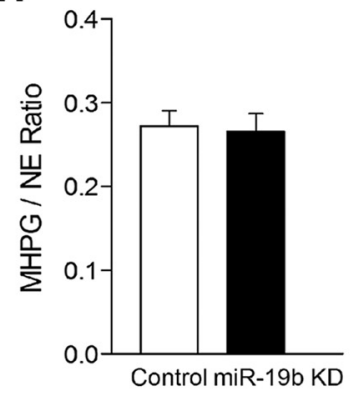

C

IL

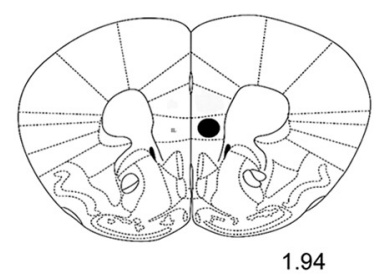

F

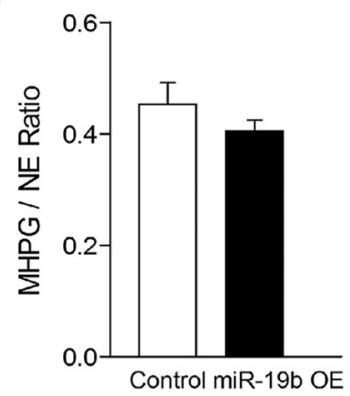

I

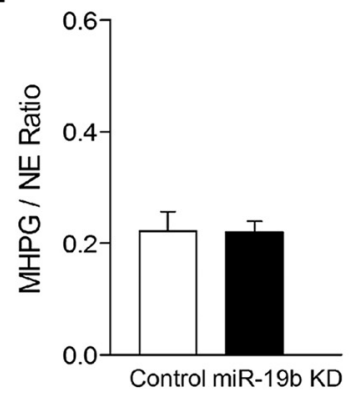

Figure 8. miR-19b OE and KD mice showed a reduction of MHPG:NE ratio in the hippocampus. $A-C$, Schematic illustration adopted from Paxinos and Franklin digital mouse brain atlas showing the nuclei analyzed in the MHPG:NE ratio measurements. Analysis of the MHPG:NE ratio in the CA1d $(\boldsymbol{D}, \boldsymbol{G}), \operatorname{PrL}(\boldsymbol{E}, \boldsymbol{H})$, and IL $(\boldsymbol{F}, \boldsymbol{I})$ brain regions $(n=10)$.

regulation of Adrb1 levels may be important for the coping of mice with stressful challenges. Low levels of Adrb1 that mediate a decrease in memory consolidation might pan out as beneficial to accommodate stressful events. Several previously published studies have highlighted adrenergic dysregulation in PTSD human studies (Southwick et al., 1999; Strawn and Geracioti, 2008; Krystal and Neumeister, 2009; Liberzon et al., 2014), suggesting an important role for the adrenergic system in coping with stressful events.

Social defeat mice have been shown previously to exhibit higher freezing time in the auditory cue test (Yu et al., 2011). Our current findings show that as a consequence of chronic stress, miR-19b levels are elevated in the amygdala, and when chronically overexpressed in the BLA caused lowering of the freezing time in the cue test. Although these findings may appear as contradicting, the experimental approaches are fundamentally different and the final behavioral readout could be influenced by multiple different factors. The CSD protocol is associated with multiple molecular and cellular changes that collectively translated, among others, into increase freezing time in the auditory cue test. Although miR-19b levels are upregulated following exposure to CSD protocol, the overexpression of miR-19b in naive mice are mechanistically very different from exposing the mice to CSD. Clearly, the overexpression of BLA-miR-19b does not represent all the changes occurring following CSD protocol, which will be also reflected in the behavioral and physiological phenotype of these mice. Additional possible factor that may contribute for these differences is the expression kinetics of the endogenous miR-19b in the BLA following stressful challenge. Here, we demonstrate a significant increase in miR-19b in the BLA of mice $8 \mathrm{~d}$ following the termination of the CSD protocol. This upregulation could be transient, permanent, or even exhibit a more complex pattern of expression kinetics and therefore the constitutive overexpression of the virally mediated miR-19b in the BLA not necessarily mimicked the endogenous situation. Nevertheless, the demonstrated repressive effect of miR-19b on Adrb1 levels and its downstream behavioral and cellular effects persist.

Whereas the three subtypes of the $\beta$ adrenergic receptors are expressed in different tissues, i.e., betal is expressed by heart cardiomyocytes, beta 2 is the dominant subtype distributed in the lungs (Carstairs et al., 1985), and beta3 is expressed in adipose tissue (Krief et al., 1993), all three are expressed in the CNS (Insel, 1993). Adrb1 and Adrb2 are both expressed in neurons of the BLA and not in astrocytes. In addition, whereas Adrb 1 is uniquely detected in the cytoplasm, Adrb2 has been shown to be present in both the cytoplasm and nucleus (Qu et al., 2008). This may indicate that each of these receptors have a distinct mechanism of action and may be differentially regulated. Adrb2 has been shown to be controlled in vitro in lung epithelial $\mathrm{H} 292$ cells by the miR let-7f. Let-7 expression increases with age (Nishino et al., 2008) and thus its regulation of Adrb2 in the BLA may be mediated through an age-related mechanism, although our analysis shows that Adrb1 is regulated in the BLA by stress. Previously, it has 

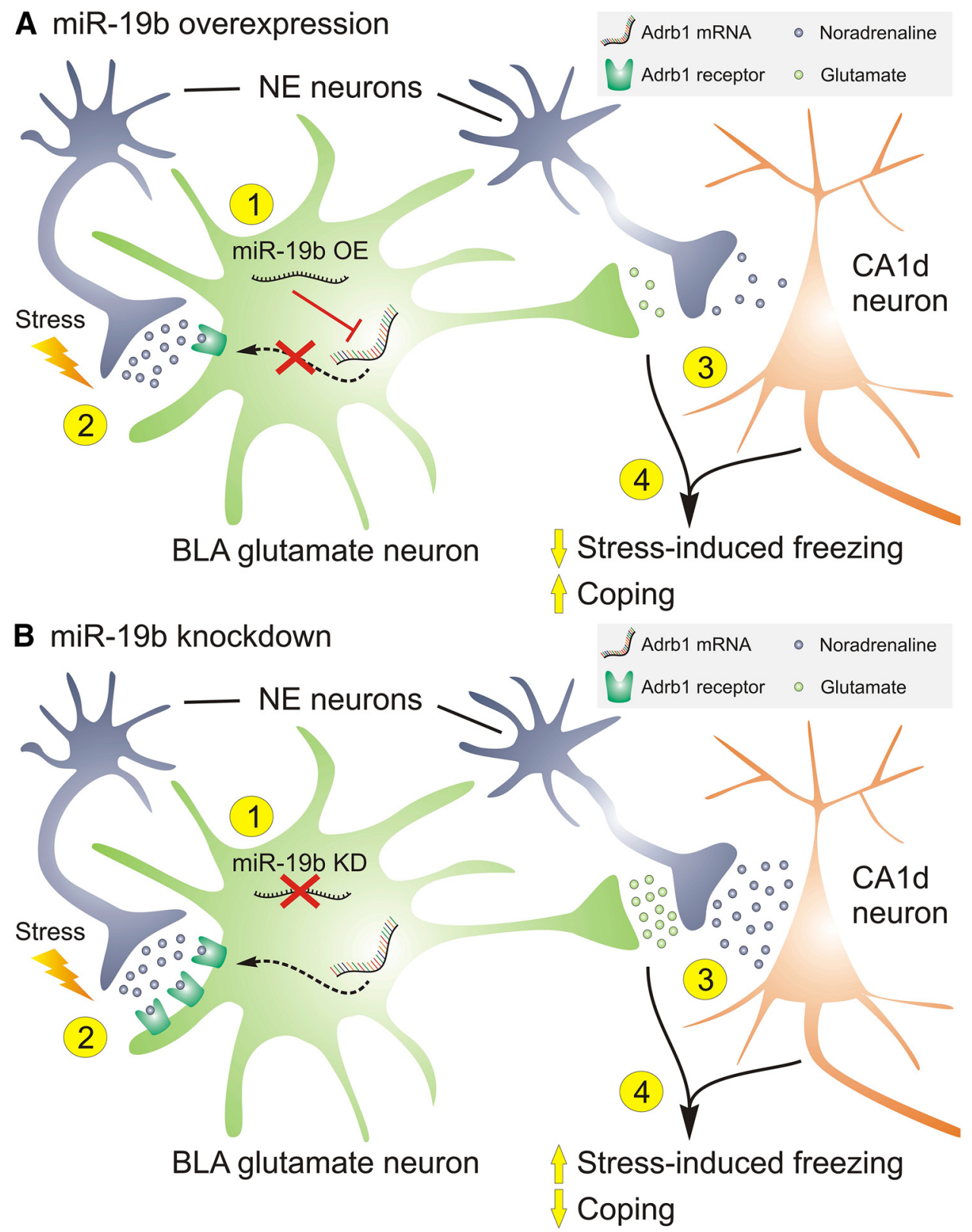

Figure 9. Putative model illustrating the effects of either miR-19b OE $(\boldsymbol{A})$ or miR-19b knockdown (KD; $\boldsymbol{B})$ in the BLA on NE neurotransmission in downstream limbic structures, such as $C A 1 d$ and the resulting changes in coping behavior. Stress-induced activation of NE afferents (Morilak et al., 2005; Itoi and Sugimoto, 2010) results in excitation of subpopulations of BLA principle neurons through agonism of $\beta$-adrenergic receptors (Ferry and McGaugh, 2000; Buffalari and Grace, 2007); therefore, in $\boldsymbol{A}$, (1) miR-19b OE in the BLA reduces Adrb1 signaling through RNA transcript degradation or translation inhibition, which leads to (2) reduced stress-induced activation of BLA glutamatergic projection neurons by NE afferents. Together with evidence that BLA glutamatergic projection neurons target the hippocampal formation (Sparta et al., 2014), including the CA1d region (Pikkarainen et al., 1999; Pitkänen et al., 2000), and these neurons are thought to be important for fear-related behavioral responses and memory processes (Davis, 1992; Herry et al., 2008; Zimmerman and Maren, 2010), as well as evidence that glutamate regulates hippocampal NE release through modulation of presynaptic NE terminals (Russell and Wiggins, 2000; Luccini et al., 2007; Howells and Russell, 2008; Dazzi et al., 2011), (3) it is probable that the decreased stress-induced activation of BLA glutamatergic projections results in diminished stress-induced presynaptic stimulation of NE release in the CA1d and consequently, and (4) reduced stress-induced freezing in cued fear conditioning and increased coping. Conversely, in $\boldsymbol{B},(1)$ miR-19b KD in the BLA facilitates Adrb1 signaling resulting in (2) increased stress-induced activation of BLA glutamatergic projection neurons by NE afferents. (3) The greater stress-induced activation of BLA glutamatergic projections results in augmented stress-induced presynaptic stimulation of NE release in the CA1d and consequently, and (4) increased stress-induced freezing and decreased coping.

been shown that the blockade of Adrb1 and Adrb2 in the BLA immediately after conditioning of rats resulted in a significantly lower freezing score in the auditory test performed $24 \mathrm{~h}$ postconditioning, indicating that both receptors are important for the formation of auditory fear memory (Qu et al., 2008). Our data implicate that miR-19b targets specifically Adrb1 and not Adrb2, suggesting a nonredundant function for Adrb1 in the stress response. This is consistent with studies by Qu et al. (2008) dem- onstrating that blocking either Adrb1 or Adrb2 was sufficient to cause a severe deficit in auditory fear memory. Consistent with blocking specifically neuronal but not astrocyte Adrb1, the virus used for injection in our miR-19b overexpressing experiments included a neuronal specific synapsin promoter. However, it is conceivable that the injection of miR-19b into the BLA affected other potential mRNA targets in the neurons. For example, miR$19 \mathrm{~b}$ can potentially target the cannabinoid receptor type 1 (CB1). 
CB1 has a 3' UTR of $3.8 \mathrm{~kb}$ with two seed matches for miR-19b (one conserved and one less conserved). CB1 plays an important role in memory consolidation in the model proposed by Hill and McEwen (2009) by releasing GABA inhibition in the BLA neurons and inducing noradrenaline release, promoting memory consolidation in the BLA.

Whereas the mice injected with miR-19b overexpressing or knockdown viruses showed a significant difference in freezing time in the cue test, no changes were observed in their freezing duration in the habituation period. Similarly, no changes were observed in their locomotor activity at the anxiety-like behavior tests or the homecage locomotor measurements. Both observations indicate that there were no motor differences between the groups and the change in freezing time resulted from a specific change in memory consolidation rather than alterations in motor function.

MiR-19b might be part of a group of miRs controlling different target genes that contribute to memory consolidation. For example, overexpression of miR-182 has been implicated recently in disruption of memory consolidation in the lateral amygdala of rats (Griggs et al., 2013). Griggs et al. (2013) showed that overexpression of miR182 in the lateral amygdala represses expression of cortactin and Ras-related C3 botulinum toxin substrate 1 (Rho family, small GTP binding protein Rac1; Rac1) following auditory fear conditioning. The levels of miR-128b were demonstrated to be elevated in the infralimbic prefrontal cortex following fear extinction learning in mice, suggesting a role for this $\mathrm{miR}$ in facilitating the formation of a fear extinction memory through targeting of the plasticityrelated gene, regulator of calmodulin signaling (Rcs; Lin et al., 2011). Finally, miR-132 overexpression was demonstrated to cause impaired plasticity and a functional deficit in short-term recognition memory (Scott et al., 2012).

In summary, we have identified miR-19b as an important chronic stress-induced regulator of amygdalar Adrb1 and its subsequent behavioral functions. A putative model illustrated in Figure 9 describe the effects of either miR-19b overexpression or miR-19b knockdown in the BLA on NE neurotransmission in downstream limbic structures, such as the CA1 region of the dorsal hippocampus, and the resulted changes in coping behavior. MiR-19b overexpression in the BLA reduces Adrb1 signaling through RNA transcript degradation or translation inhibition, which leads to reduced stress-induced activation of BLA glutamatergic projection neurons by NE afferents. The decreased stress-induced activation of BLA glutamatergic projection results in diminished stress-induced presynaptic stimulation of $\mathrm{NE}$ release in the CA1d and consequently reduce stress-induced freezing in the cued fear conditioning and increase coping. Conversely, miR-19b knockdown in the BLA facilitates Adrb1 signaling resulting in increased stress-induced activation of BLA glutamatergic projection neurons by NE afferents. The greater stress-induced activation of BLA glutamatergic projections results in augmented stress-induced presynaptic stimulation of NE release in the CA1d and consequently increase stress-induced freezing and decrease coping. Spatial regulation of Adrb1 by miRNA enables the neurons in the BLA to provide an appropriate response in stress conditions enabling the animal to accommodate its behavior to the changing conditions.

\section{References}

Betel D, Wilson M, Gabow A, Marks DS, Sander C (2008) The microRNA.org resource: targets and expression. Nucleic Acids Res 36:D149D153. CrossRef Medline

Buffalari DM, Grace AA (2007) Noradrenergic modulation of basolateral amygdala neuronal activity: opposing influences of alpha- 2 and beta receptor activation. J Neurosci 27:12358-12366. CrossRef Medline
Carstairs JR, Nimmo AJ, Barnes PJ (1985) Autoradiographic visualization of beta-adrenoceptor subtypes in human lung. Am Rev Resp Dis 132:541547. Medline

Chen A, Perrin M, Brar B, Li C, Jamieson P, Digruccio M, Lewis K, Vale W (2005) Mouse corticotropin-releasing factor receptor type 2alpha gene: isolation, distribution, pharmacological characterization and regulation by stress and glucocorticoids. Mol Endocrinol 19:441-458. CrossRef Medline

Davis M (1992) The role of the amygdala in fear and anxiety. Ann Rev Neurosci 15:353-375. CrossRef Medline

Dazzi L, Matzeu A, Biggio G (2011) Role of ionotropic glutamate receptors in the regulation of hippocampal norepinephrine output in vivo. Brain Res 1386:41-49. CrossRef Medline

Elliott E, Ezra-Nevo G, Regev L, Neufeld-Cohen A, Chen A (2010) Resilience to social stress coincides with functional DNA methylation of the Crf gene in adult mice. Nat Neurosci 13:1351-1353. CrossRef Medline

Evans AK, Reinders N, Ashford KA, Christie IN, Wakerley JB, Lowry CA (2008) Evidence for serotonin synthesis-dependent regulation of in vitro neuronal firing rates in the midbrain raphe complex. Eur J Pharmacol 590:136-149. CrossRef Medline

Ferry B, McGaugh JL (2000) Role of amygdala norepinephrine in mediating stress hormone regulation of memory storage. Acta Pharmacol Sin 21: 481-493. Medline

Ferry B, Magistretti PJ, Pralong E (1997) Noradrenaline modulates glutamate-mediated neurotransmission in the rat basolateral amygdala in vitro. Eur J Neurosci 9:1356-1364. CrossRef Medline

Fortaleza EA, Scopinho AA, Correê FM (2012) Beta-adrenoceptors in the medial amygdaloid nucleus modulate the tachycardiac response to restraint stress in rats. Neuroscience 227:170-179. CrossRef Medline

Fu A, Li X, Zhao B (2008) Role of beta1-adrenoceptor in the basolateral amygdala of rats with anxiety-like behavior. Brain Res 1211:85-92. CrossRef Medline

Galvez R, Mesches MH, McGaugh JL (1996) Norepinephrine release in the amygdala in response to footshock stimulation. Neurobiol Learn Mem 66:253-257. CrossRef Medline

Gean PW, Huang CC, Lin JH, Tsai JJ (1992) Sustained enhancement of NMDA receptor-mediated synaptic potential by isoproterenol in rat amygdalar slices. Brain Res 594:331-334. CrossRef Medline

Griggs EM, Young EJ, Rumbaugh G, Miller CA (2013) MicroRNA-182 regulates amygdala-dependent memory formation. J Neurosci 33:17341740. CrossRef Medline

Haramati S, Navon I, Issler O, Ezra-Nevo G, Gil S, Zwang R, Hornstein E, Chen A (2011) MicroRNA as repressors of stress-induced anxiety: the case of amygdalar miR-34. J Neurosci 31:14191-14203. CrossRef Medline

Hatfield T, McGaugh JL (1999) Norepinephrine infused into the basolateral amygdala posttraining enhances retention in a spatial water maze task. Neurobiol Learn Mem 71:232-239. CrossRef Medline

Heal DJ, Prow MR, Buckett WR (1989) Measurement of 3-methoxy-4hydroxyphenylglycol (MHPG) in mouse brain by h.p.l.c. with electrochemical detection, as an index of noradrenaline utilisation and presynaptic alpha 2-adrenoceptor function. Br J Pharmacol 96:547-556. CrossRef Medline

Herry C, Ciocchi S, Senn V, Demmou L, Müller C, Lüthi A (2008) Switching on and off fear by distinct neuronal circuits. Nature 454:600-606. CrossRef Medline

Hill MN, McEwen BS (2009) Endocannabinoids: the silent partner of glucocorticoids in the synapse. Proc Natl Acad Sci U S A 106:4579-4580. CrossRef Medline

Hioki H, Kameda H, Nakamura H, Okunomiya T, Ohira K, Nakamura K, Kuroda M, Furuta T, Kaneko T (2007) Efficient gene transduction of neurons by lentivirus with enhanced neuron-specific promoters. Gene Ther 14:872-882. CrossRef Medline

Howells FM, Russell VA (2008) Glutamate-stimulated release of norepinephrine in hippocampal slices of animal models of attention-deficit/ hyperactivity disorder (spontaneously hypertensive rat) and depression/ anxiety-like behaviours (Wistar-Kyoto rat). Brain Res 1200:107-115. CrossRef Medline

Huang CC, Hsu KS, Gean PW (1996) Isoproterenol potentiates synaptic transmission primarily by enhancing presynaptic calcium influx via $\mathrm{P}$ and/or Q-type calcium channels in the rat amygdala. J Neurosci 16:10261033. Medline

Insel PA (1993) Adrenergic receptors, G proteins, and cell regulation: im- 
plications for aging research. Exp Gerontol 28:341-348. CrossRef Medline

Issler O, Haramati S, Paul ED, Maeno H, Navon I, Zwang R, Gil S, Mayberg HS, Dunlop BW, Menke A, Awatramani R, Binder EB, Deneris ES, Lowry CA, Chen A (2014) MicroRNA 135 is essential for chronic stress resiliency, antidepressant efficacy, and intact serotonergic activity. Neuron 83:344-360. CrossRef Medline

Itoi K, Sugimoto N (2010) The brainstem noradrenergic systems in stress, anxiety and depression. J Neuroendocrinol 22:355-361. CrossRef Medline

Kim JJ, Fanselow MS (1992) Modality-specific retrograde amnesia of fear. Science 256:675-677. CrossRef Medline

Krief S, Lönnqvist F, Raimbault S, Baude B, Van Spronsen A, Arner P, Strosberg AD, Ricquier D, Emorine LJ (1993) Tissue distribution of beta 3-adrenergic receptor mRNA in man. J Clin Invest 91:344-349. CrossRef Medline

Krishnan V, Han MH, Graham DL, Berton O, Renthal W, Russo SJ, Laplant Q, Graham A, Lutter M, Lagace DC, Ghose S, Reister R, Tannous P, Green TA, Neve RL, Chakravarty S, Kumar A, Eisch AJ, Self DW, Lee FS, et al. (2007) Molecular adaptations underlying susceptibility and resistance to social defeat in brain reward regions. Cell 131:391-404. CrossRef Medline

Krystal JH, Neumeister A (2009) Noradrenergic and serotonergic mechanisms in the neurobiology of posttraumatic stress disorder and resilience. Brain Res 1293:13-23. CrossRef Medline

Kuperman Y, Issler O, Regev L, Musseri I, Navon I, Neufeld-Cohen A, Gil S, Chen A (2010) Perifornical urocortin-3 mediates the link between stress-induced anxiety and energy homeostasis. Proc Natl Acad Sci U S A 107:8393-8398. CrossRef Medline

Lebow M, Neufeld-Cohen A, Kuperman Y, Tsoory M, Gil S, Chen A (2012) Susceptibility to PTSD-like behavior is mediated by corticotropinreleasing factor receptor type 2 levels in the bed nucleus of the stria terminalis. J Neurosci 32:6906-6916. CrossRef Medline

Liberzon I, King AP, Ressler KJ, Almli LM, Zhang P, Ma ST, Cohen GH, Tamburrino MB, Calabrese JR, Galea S (2014) Interaction of the $A D R B 2$ gene polymorphism with childhood trauma in predicting adult symptoms of posttraumatic stress disorder. JAMA Psychiatry 71:11741182. CrossRef Medline

Lin Q, Wei W, Coelho CM, Li X, Baker-Andresen D, Dudley K, Ratnu VS, Boskovic Z, Kobor MS, Sun YE, Bredy TW (2011) The brain-specific microRNA miR-128b regulates the formation of fear-extinction memory. Nat Neurosci 14:1115-1117. CrossRef Medline

Luccini E, Musante V, Neri E, Brambilla Bas M, Severi P, Raiteri M, Pittaluga A (2007) Functional interactions between presynaptic NMDA receptors and metabotropic glutamate receptors co-expressed on rat and human noradrenergic terminals. Br J Pharmacol 151:1087-1094. CrossRef Medline

McGaugh JL, Cahill L, Roozendaal B (1996) Involvement of the amygdala in memory storage: interaction with other brain systems. Proc Natl Acad Sci U S A 93:13508-13514. CrossRef Medline

Meerson A, Cacheaux L, Goosens KA, Sapolsky RM, Soreq H, Kaufer D (2010) Changes in brain MicroRNAs contribute to cholinergic stress reactions. J Mol Neurosci 40:47-55. CrossRef Medline

Meister G, Landthaler M, Patkaniowska A, Dorsett Y, Teng G, Tuschl T (2004) Human Argonaute2 mediates RNA cleavage targeted by miRNAs and siRNAs. Mol Cell 15:185-197. CrossRef Medline

Morilak DA, Barrera G, Echevarria DJ, Garcia AS, Hernandez A, Ma S, Petre CO (2005) Role of brain norepinephrine in the behavioral response to stress. Prog Neuropsychopharmacol Biol Psychiatry 29:1214-1224. CrossRef Medline

Neufeld-Cohen A, Tsoory MM, Evans AK, Getselter D, Gil S, Lowry CA, Vale WW, Chen A (2010) A triple urocortin knockout mouse model reveals an essential role for urocortins in stress recovery. Proc Natl Acad Sci U S A 107:19020-19025. CrossRef Medline

Nishino J, Kim I, Chada K, Morrison SJ (2008) Hmga2 promotes neural stem cell self-renewal in young but not old mice by reducing p16Ink4a and p19Arf expression. Cell 135:227-239. CrossRef Medline

Palkovits M, Brownstein MJ (1988) Maps and guide to microdissection of the rat brain. New York: Elsevier.

Pikkarainen M, Rönkkö S, Savander V, Insausti R, Pitkänen A (1999) Projections from the lateral, basal, and accessory basal nuclei of the amygdala to the hippocampal formation in rat. J Comp Neurol 403:229-260. CrossRef Medline

Pitkänen A, Pikkarainen M, Nurminen N, Ylinen A (2000) Reciprocal con- nections between the amygdala and the hippocampal formation, perirhinal cortex, and postrhinal cortex in rat. A review. Ann N Y Acad Sci 911:369-391. CrossRef Medline

Qu LL, Guo NN, Li BM (2008) Beta1- and beta2-adrenoceptors in basolateral nucleus of amygdala and their roles in consolidation of fear memory in rats. Hippocampus 18:1131-1139. CrossRef Medline

Regev L, Tsoory M, Gil S, Chen A (2012) Site-specific genetic manipulation of amygdala corticotropin-releasing factor reveals its imperative role in mediating behavioral response to challenge. Biol Psychiatry 71:317-326. CrossRef Medline

Rodriguez-Gonzalez A, Lin T, Ikeda AK, Simms-Waldrip T, Fu C, Sakamoto KM (2008) Role of the aggresome pathway in cancer: targeting histone deacetylase 6-dependent protein degradation. Cancer Res 68:2557-2560. CrossRef Medline

Roozendaal B (2000) 1999 Curt P. Richter award: glucocorticoids and the regulation of memory consolidation. Psychoneuroendocrinology 25: 213-238. CrossRef Medline

Roozendaal B, Hahn EL, Nathan SV, de Quervain DJ, McGaugh JL (2004) Glucocorticoid effects on memory retrieval require concurrent noradrenergic activity in the hippocampus and basolateral amygdala. J Neurosci 24:8161-8169. CrossRef Medline

Roozendaal B, Okuda S, Van der Zee EA, McGaugh JL (2006a) Glucocorticoid enhancement of memory requires arousal-induced noradrenergic activation in the basolateral amygdala. Proc Natl Acad Sci U S A 103: 6741-6746. CrossRef Medline

Roozendaal B, Hui GK, Hui IR, Berlau DJ, McGaugh JL, Weinberger NM (2006b) Basolateral amygdala noradrenergic activity mediates corticosteroneinduced enhancement of auditory fear conditioning. Neurobiol Learn Mem 86:249-255. CrossRef Medline

Rudoy CA, Van Bockstaele EJ (2007) Betaxolol, a selective beta(1)adrenergic receptor antagonist, diminishes anxiety-like behavior during early withdrawal from chronic cocaine administration in rats. Prog Neuropsychopharmacol Biol Psychiatry 31:1119-1129. CrossRef Medline

Russell VA, Wiggins TM (2000) Increased glutamate-stimulated norepinephrine release from prefrontal cortex slices of spontaneously hypertensive rats. Metab Brain Dis 15:297-304. CrossRef Medline

Schwabe L, Joëls M, Roozendaal B, Wolf OT, Oitzl MS (2012) Stress effects on memory: an update and integration. Neurosci Biobehav Rev 36:17401749. CrossRef Medline

Scott HL, Tamagnini F, Narduzzo KE, Howarth JL, Lee YB, Wong LF, Brown MW, Warburton EC, Bashir ZI, Uney JB (2012) MicroRNA-132 regulates recognition memory and synaptic plasticity in the perirhinal cortex. Eur J Neurosci 36:2941-2948. CrossRef Medline

Southwick SM, Bremner JD, Rasmusson A, Morgan CA 3rd, Arnsten A, Charney DS (1999) Role of norepinephrine in the pathophysiology and treatment of posttraumatic stress disorder. Biol Psychiatry 46:1192-1204. CrossRef Medline

Sparta DR, Smithuis J, Stamatakis AM, Jennings JH, Kantak PA, Ung RL, Stuber GD (2014) Inhibition of projections from the basolateral amygdala to the entorhinal cortex disrupts the acquisition of contextual fear. Front Behav Neurosci 8:129. CrossRef Medline

Strawn JR, Geracioti TD Jr (2008) Noradrenergic dysfunction and the psychopharmacology of posttraumatic stress disorder. Depress Anxiety 25: 260-271. CrossRef Medline

Sztainberg Y, Kuperman Y, Tsoory M, Lebow M, Chen A (2010) The anxiolytic effect of environmental enrichment is mediated via amygdalar CRF receptor type 1. Mol Psychiatry 15:905-917. CrossRef Medline

Tiscornia G, Singer O, Verma IM (2006) Production and purification of lentiviral vectors. Nat Protoc 1:241-245. CrossRef Medline

Uchida S, Nishida A, Hara K, Kamemoto T, Suetsugi M, Fujimoto M, Watanuki T, Wakabayashi Y, Otsuki K, McEwen BS, Watanabe Y (2008) Characterization of the vulnerability to repeated stress in Fischer 344 rats: possible involvement of microRNA-mediated down-regulation of the glucocorticoid receptor. Eur J Neurosci 27:2250-2261. CrossRef Medline

Yu T, Guo M, Garza J, Rendon S, Sun XL, Zhang W, Lu XY (2011) Cognitive and neural correlates of depression-like behaviour in socially defeated mice: an animal model of depression with cognitive dysfunction. Int J Neuropsychopharmacol 14:303-317. CrossRef Medline

Zimmerman JM, Maren S (2010) NMDA receptor antagonism in the basolateral but not central amygdala blocks the extinction of Pavlovian fear conditioning in rats. Eur J Neurosci 31:1664-1670. CrossRef Medline 